\title{
PERSUASION IN ADVERTISEMENTS OF FREIGHT FORWARDING
}

\author{
Galuh Dynasty Mula Suparma*, Chatarini Septi Ngudi Lestari \\ Sekolah Tinggi Ilmu Bahasa Dan Sastra Satya Widya, East Java, Indonesia \\ g.dynasty.m.s@gmail.com*
}

\begin{abstract}
This study is concerned with persuasion in advertisements of freight forwarding which were uploaded within 2019 on YouTube based on discourse analysis perspective. This study aims to find out the kinds of persuasive strategies and the way how persuasions are used. To reach those goals, Beebe \& Beebe's theory of persuasive strategies and Makosky's theory of persuasion technique are applied. Qualitative research employed since the data are in the form of words, phrases, or even sentences. The result showed that the kind of persuasive strategy which mostly performed in freight forwarding advertisements is causal reasoning (49). Moreover, the way of using persuasion in the form of persuasion technique which mostly applied is the appeal to or creation of needs (92).
\end{abstract}

Keywords: Persuasion, Advertisement, Freight Forwarding, YouTube

\section{Introduction}

Language as a fundamental thing in this world plays a great role in supporting and building life. It makes a discipline that specifically studies language is raised. Linguistics is a scientific study of language. Discourse analysis is a branch of linguistics which deals with language which applied in communications. Brown and Yule (1983) state that the analysis of discourse is, necessarily, the analysis of language in use, the discourse analysis is committed to an investigation of what that language is used for.

The term persuasive concerns with deceiving someone else's mind so they have same vision with the persuader and are able to do something that the persuader implicitly wants. As stated by Kinneavy (1971) persuasive is a kind of discourse which is primarily focused on the decoder and attempts to elicit from him specific action or emotion or conviction. Therefore, persuasion is a kind of discourse which concentrates on the hearer as the main goal of the communication. Furthermore, Beebe and Beebe (2015) state that persuasion is the process of changing or reinforcing attitudes, beliefs, values, or behavior. Adapting Aristotle's persuasion ingredients, Beebe \& Beebe (2015) mention that there are seventeen kinds of persuasive strategies, they are; competence, trustworthiness, dynamism, inductive reasoning, deductive reasoning, causal reasoning, credible evidence, new evidence, specific evidence, use evidence to 


\section{International Journal of Linguistics and Discourse Analytics}

Vol.2, No.2, March 2021

P-ISSN 2721-8899 E-ISSN 2721-8880

tell a story, concrete examples, emotion-arousing words, nonverbal behavior, visual image, metaphors and similes, fear appeals, and shared myths.

Kinneavy (1971) mentions that there are three clear examples of persuasive discourse, one of them is advertising. In line with the theory, Jafari and Mahadi (2014) also state that, in fact, advertisements are the excellent example of persuasion. Persuasion in advertisements is using some additional techniques which differs it with persuasion in people's speech. Makosky (1985) states that there are three additional techniques in performing persuasion in advertisements, those are; the appeal to or creation of needs, social and prestige suggestion, and the use of emotionally loaded words and images. In line with this study, the researcher uses advertisement as source of data, especially, freight forwarding's advertisements. Advertisement is a paid-for communication intended to inform and/or persuade one or more people (Fletcher, 2010). While, freight forwarding is an activity of providing a service for people or companies who want to deliver their items from one country to another, in other words, export-import activity.

Good advertisements of freight forwarding are really needed because freight forwarding holds necessary roles in helping companies and people to handle their flow of export-import activities. The freight forwarding's advertisements are taken from YouTube channel which have shared during 2019. The analysis of this study is focused on the persuasions which appear in freight forwarding's advertisements, those are the kinds of persuasive strategies and the ways how persuasions are applied (called persuasion techniques)

\section{Methods}

In conducting this research, the writer uses qualitative research design since the data collected are in the form of words or pictures rather than numbers; and the writer also uses descriptive research method since this research deals with fact and concerns with the present and phenomenon under investigation. In this study, the writer takes video advertisements of freight forwarding as the source of data. The videos are taken from a website for video sharing called YouTube which shared within 2019.

The writer watches the video of freight forwarding advertisements carefully in order to understand what are the models or narrators saying about and how are their body languages. After watching the videos intensely, it is time to transcribe them into texts to make it easier for identifying the persuasions. Afterwards, the writer identifies the data which are related to the topic by giving number and underlining the data which are concerned with persuasion. After doing the processes of collecting data, the writer then move to the steps of data analysis. The very first step the writer should do, is, describing the general description of the advertisement in order to give an overview about what condition which depicted in the advertisement. After that, the writer classifies the kinds of persuasive strategies which found in the video's transcription 


\section{International Journal of Linguistics and Discourse Analytics}

Vol.2, No.2, March 2021

P-ISSN 2721-8899 E-ISSN 2721-8880

based on Beebe \& Beebe (2015) theory of persuasive strategies; and describes the ways of using the persuasion based on the Vivian Parker Makosky (1985) theory of persuasion techniques.

\section{Findings and Discussion}

After analyzing the whole identified data (133 data) which are taken from 18 freight forwarding advertisements which were uploaded on YouTube in 2019, it found that there are fifteen kinds of persuasive strategies out of seventeen kinds of persuasive strategies. They are competence; trustworthiness; dynamism; inductive reasoning; deductive reasoning; causal reasoning; credible evidence; new evidence; specific evidence; use evidence to tell a story; concrete example; emotion-arousing words; nonverbal behavior; visual image to evoke emotion; and appropriate fear appeals; while use appropriate metaphor and simile, and tap into shared myths did not appear. To make them clear, it can be seen in the following table as follows:

Table 1. Kinds of Persuasive Strategies

\begin{tabular}{|c|c|c|c|}
\hline \multirow{2}{*}{ No. } & \multirow{2}{*}{$\begin{array}{c}\text { Kinds of Persuasive } \\
\text { Strategies }\end{array}$} & \multicolumn{2}{|l|}{ Data } \\
\hline & & Advertisements & Frequency \\
\hline 1 & Competence & $1,4,6,8,9,10,11,13,14,16,17,18$ & 36 \\
\hline 2 & Trustworthiness & $7,8,9,12$ & 27 \\
\hline 3 & Dynamism & 12 & 1 \\
\hline 4 & Inductive Reasoning & $1,3,5,7,8,9,13,14,15,16,17,18$ & 16 \\
\hline 5 & Deductive Reasoning & 11 & 3 \\
\hline 6 & Causal Reasoning & $\begin{array}{c}1,2,3,4,5,6,10,11,14,15,16,17 \\
18\end{array}$ & 49 \\
\hline 7 & Credible Evidence & 7,12 & 18 \\
\hline 8 & New Evidence & $1,5,8,9$ & 12 \\
\hline 9 & Specific Evidence & $1,2,3,4,5,6,7,10,11,12,14,17,18$ & 22 \\
\hline 10 & Use Evidence to Tell a Story & 12 & 12 \\
\hline 11 & Concrete Example & 7,12 & 9 \\
\hline 12 & Emotion-Arousing Words & $1,7,11,12,15,18$ & 13 \\
\hline 13 & Nonverbal Behaviour & 14 & 2 \\
\hline 14 & $\begin{array}{l}\text { Visual Image to Evoke } \\
\text { Emotion }\end{array}$ & 11 & 1 \\
\hline 15 & $\begin{array}{l}\text { Appropriate Metaphor and } \\
\text { Simile }\end{array}$ & - & 0 \\
\hline 16 & Appropriate Fear Appeal & 1 & 3 \\
\hline 17 & Tap into Shared Myths & - & 0 \\
\hline
\end{tabular}




\section{International Journal of Linguistics and Discourse Analytics}

Vol.2, No.2, March 2021

P-ISSN 2721-8899 E-ISSN 2721-8880

Table 1 shows the result of analysis of kinds of persuasive strategies taken from 18 freight forwarding advertisements which were uploaded on YouTube in 2019. From the table, it can be known that the dominant strategies which are used in these advertisements are causal reasoning (49), then it is followed by competence (36), trustworthiness (27), specific evidence (22), credible evidence (18), inductive reasoning (16), emotion-arousing words (13), new evidence (12), use evidence to tell a story (12), concrete examples (9), deductive reasoning (3), appropriate fear appeals (3), non-verbal behavior (2), dynamism (1), and visual image to evoke emotion (1); while use appropriate metaphor and simile, and tap into shared myths are not used.

Referring to the description above, it can be accounted that persuasive strategies are very important for freight forwarding advertisements; each strategy has its own strength in changing or reinforcing people's mind and thoughts. Persuasive strategies make advertisements work better in influencing people; and the right choice of persuasive strategies make the advertisements work even much better.

Causal reasoning strategy is a strategy which relates two or more events or cases which have such cause and effect which are related one another. Concerning the findings of the analysis, causal reasoning strategy is the most frequent strategy used in 18 freight forwarding advertisements. It appeared 49 times. It can be seen in advertisement 1 ( 2 data); advertisement 2 (7 data); advertisement 3 (7 data); advertisement 4 (3 data); advertisement 5 (3 data); advertisement 6 (5 data); advertisement 10 (3 data); advertisement 11 (3 data); advertisement 14 (3 data); advertisement 15 (4 data); advertisement 16 (5 data); advertisement 17 (2 data); and advertisement 18 ( 2 data). The domination of this strategy means that most of freight forwarding advertisers tend to relate two or more cases which have such cause and effect relation one another; in this case, those cases are excellences or facilities and guaranteed benefits. For examples; "all you have to do is to provide your shipping details and receive the most competitive quotation instantly" [Ads 1, (1.2)] and "make your life easier" [Ads 1, (1.3)] show cause and effect relation where data (1.2) depicts a known fact that Kuehne + Nagel creates a new platform for instant quotation, then data (1.3) depicts a predicted result that their platform can make their customers' life is easier; "managed through our dedicated healthcare control tower" [Ads 18, (18.3)] and "provide visibility, consolidation, and optimization" [Ads 18, (18.4)] indicate a fact that Yusen has centralized management which they predict that it can provide better benefits for their customers.

Competence strategy is a strategy where the speakers make themselves look knowledgeable for what they are being talked about. In line with the findings, this strategy is the second frequently used in 18 freight forwarding advertisements after causal reasoning. It is applied 36 times. It can be found in advertisement 1 ( 3 data); advertisement 4 ( 3 data); advertisement 6 (3 data); advertisement 8 ( 6 data); advertisement 9 (1 data); advertisement 10 (3 
International Journal of Linguistics and Discourse Analytics

Vol.2, No.2, March 2021

P-ISSN 2721-8899 E-ISSN 2721-8880

data); advertisement 11 (6 data); advertisement 13 (3 data); advertisement 14 (2 data); advertisement 16 ( 2 data); advertisement 17 (3 data); and advertisement 18 ( 1 data). The application of this strategy depicts how the freight forwarding advertisers compete to make themselves look knowledgeable for what they are talking about by presenting their understanding toward their customers and their excellences in handling many cases. For examples; "manage the needed documentations" [Ads 4, (4.3)] depicts DHL's insight about what thing is essentially needed in handling dangerous cargoes, then DHL will be considered knowledgeable about dangerous cargoes by pointing an essential thing which they put their attention most on this; "Operational excellence combined with digital ease of use" [Ads 9, (9.6)] asserts how DB Schenker are able to recognize people's wants and needs of simplicity, speed, and excellence; "it's about more than delivering a product, it's about getting every detail right" [Ads 18, (18.5)] shows where Yusen expose their understanding and high dedication which make audiences regard them as knowledgeable.

Trustworthiness strategy is a strategy which deals with how the speakers can build their characters in front of the hearers and make them think that the speakers are honest and worth to be trusted. Referring to the findings, this strategy is the third highly performed after competence. It is performed 27 times. It can be seen in advertisement 7 ( 6 data); advertisement 8 (4 data); advertisement 9 (5 data); and advertisement 12 (12 data). The performance of this strategy pictures how the freight forwarding advertisers compete to build the company's image in front of the audiences by giving such real proofs to make the audiences think that they are honest and worth to be trusted. For examples; "from Pointe-à-Pitre, Guadeloupe, to La Désirade, Guadeloupe" [Ads 7, (7.1)], "40 out-of-gauge components, including 8 E44 wind turbine generators" [Ads 7, (7.2)] and "complex island access roads" [Ads 7, (7.3)] portray GEODIS own experience in handling a project at France to deliver wind turbine generators, GEODIS is considered presenting real proofs from their own experience, so that the audiences will be more likely to regard them as trustworthy.

Specific evidence strategy is a strategy where the speakers tend to give concrete number or additional details to avoid ambiguity and make their persuasion become more trustworthy. In line with the findings, this strategy appeared frequently enough. It appeared 22 times. It can be found in advertisement 1 (1 data); advertisement 2 ( 2 data); advertisement 3 (2 data); advertisement 4 (1 data); advertisement 5 ( 1 data); advertisement 6 (1 data); advertisement 7 (5 data); advertisement 10 (1 data); advertisement 11 ( 1 data); advertisement 12 (3 data); advertisement 14 ( 1 data); advertisement 17 ( 2 data); and advertisement 18 (1 data). The appearance of this strategy means that freight forwarding advertisers tend to give concrete number or additional details to give certainty for audiences and make their persuasion more trustworthy. For examples; "from conventional rail to intermodal, from standard loads to special transports, from heavy goods to high value, from north to south and east to west, from 


\section{International Journal of Linguistics and Discourse Analytics}

Vol.2, No.2, March 2021

P-ISSN 2721-8899 E-ISSN 2721-8880

seaport to railport, from semi-trailer to roll-trailer" [Ads 10, (10.3)] shows where DB Schenker tend to give specific additional descriptions for what they said "broad range of multimodal customer solutions" rather than leave that ambiguous phrase itself, those specific additional descriptions bring certainty for target audiences and avoid ambiguity; "over 45.000 employees in 80 countries" [Ads 5, (5.1)] depicts DSV's tendency to give specific additional details by mentioning the number of their global employee and the number of countries they spread around the world in exact number; "Aji from Amakusa" [Ads 14, (14.1)] shows where Nippon Express tend to give specific description on the kind of fish that Dam likes and where it comes from, rather than using such ambiguous phrase like "fish from a city in Japan".

Credible evidence strategy is a strategy where the persuaders give evidences which are trustworthy, knowledgeable and coming from unbiased source; those evidences can be in the form of real experiences or testimony. Concerning the analysis' findings, this strategy is applied in highly enough times. It is used 18 times. It can be seen in advertisement 7 (6 data); and advertisement 12 (12 data). The use of this strategy shows that freight forwarding advertisers, at some points, present the real experiences of the company in handling such particular case to persuade audiences or use testimony to promote their service indirectly. For examples; "Expeditors has been great at reaching to our demands on a daily basis" [Ads 12, (12.4)] and "if we have an issue with one e-commerce order" [Ads 12, (12.5)] depict where Gabriel uses the first person point of view (we, our) to show that the story is real and he experiences it himself, his story is regarded as testimony which strong enough in persuading people; .

Inductive reasoning strategy is a strategy where the persuaders state some specific examples then reach to general conclusion. Referring to the findings, this strategy appeared in frequently enough times. It appeared 16 times and can be found in advertisement 1 ( 1 data); advertisement 3 ( 1 data); advertisement 5 (1 data); advertisement 7 (1 data); advertisement 8 (1 data); advertisement 9 (1 data); advertisement 13 (2 data); advertisement 14 (1 data); advertisement 15 (2 data); advertisement 16 (1 data); advertisement 17 (1 data); and advertisement 18 ( 3 data). The appearance of this strategy points out that freight forwarding advertisers tend to state general conclusion after mentioning their abilities, facilities, or technologies to assert and emphasis those specific examples. For examples; " make your start-up a success " [Ads 5, (5.6)] indicates a general conclusion which DSV confident and believe that their expertise and efforts are highly capable in leading and bringing the start-ups they build to success; "insight into action" [Ads 16, (16.8)] portrays a general conclusion that Yusen are logistics company that possess insight into action, so that their actions are knowledge-based and guaranteed safety after trying to convey that they have high knowledge and facilities of logistics and supply chain; "Your trusted partner in automotive logistics" [Ads 17, (17.8)] portrays a general conclusion that Yusen are worth to be regarded as trusted partner in automotive logistics after mentioning various examples which highly possible to lead to this general conclusion. 


\section{International Journal of Linguistics and Discourse Analytics}

Vol.2, No.2, March 2021

P-ISSN 2721-8899 E-ISSN 2721-8880

Emotion-arousing words strategy is a strategy which used to trigger emotional responses in the listeners. In line with the findings, this strategy performed in moderately frequent times. It is performed 13 times. It can be seen in advertisement 1 ( 3 data); advertisement 7 ( 2 data); advertisement 11 (2 data); advertisement 12 (2 data); advertisement 15 (2 data); and advertisement 18 ( 2 data). The performance of this strategy depicts that freight forwarding advertisers also try to arouse their audiences' emotion of fear, safety or happiness to implicitly show that they are understand their customers well and try to immerse the audiences into the flow of persuasion. For examples; "complex island access roads" [Ads 7, (7.3)] and "Over $25^{\circ}$ slopes" [Ads 7, (7.4)] supported with the documentation video showing GEODIS's struggle to pass the slopes point out where GEODIS show their big efforts when delivering the wind turbine generators in France, those statements are used to arouse audiences' sense of amazement because of the extremity and GEODIS's capability to make it success; "Missing shipment... "It's stuck in customs"," [Ads 11, (11.1)] and "It didn't get there on time... "It's stuck in customs"," [Ads 11, (11.2)] indicate where Expeditors try to arouse audiences' feeling of unpleasant things, everyone who ever ship their goods of course understand how it feels to lose their cargo and experience delays in delivery, so that they have to choose the right partner in shipping goods to avoid those bad experiences.

New evidence strategy is a strategy where the persuaders present up-to-date evidences or evidences which the target audiences have not heard before. Concerning the analysis findings, this strategy is also applied moderately frequent times. It is applied 12 times and can be found in advertisement 1 ( 1 data); advertisement 5 ( 3 data); advertisement 8 (6 data); and advertisement 9 ( 2 data). The application of this strategy shows that freight forwarding advertisers compete to present evidences that the audiences might not heard before to make them focus on the message in advertisement because they feel that they learn something new. For examples; "all you have to do is to provide your shipping details and receive the most competitive quotation instantly" [Ads $1,(1.2)$ ], putting down shipment details to a website then getting an instant competitive quotation is such a something new for audiences; "Get instant quotes and manage your shipment online" [Ads 9, (9.2)] and "Define your shipment with just a few clicks" [Ads 9, (9.4)] deliver such new information for people that they might never heard before; those new information are easier in catching people's attention and make them focus on the advertisement because they feel like learning something new from it.

Use evidence to tell a story strategy is a strategy where the speakers use evidence to support a story to add emotional power and make the evidences seem less abstract. Referring to the findings, this is another strategy which applied moderately frequent. It is applied 12 times. It can be seen in advertisement 12 (12 data). The application of this strategy shows that the speaker in the advertisement strengthens the evidences and adds emotional power for audiences to make them feel what the speaker feels. 
International Journal of Linguistics and Discourse Analytics

Vol.2, No.2, March 2021

P-ISSN 2721-8899 E-ISSN 2721-8880

Concrete examples strategy indicated by the use of such concrete and vivid evidences which regarded as something that happened for real. In line with the findings, this strategy appeared less frequent enough. It appeared 9 times. It can be found in advertisement 7 ( 6 data); and advertisement 12 (3 data). The appearance of this strategy indicates that, at some points, freight forwarding advertisers deliver something that happened for real such as the company's own experiences to make their persuasion stronger in influencing audiences' mind. For examples; "complex island access roads" [Ads 7, (7.3)] and "Over $25^{\circ}$ slopes" [Ads 7, (7.4)] portray GEODIS own experience in handling a project at France to deliver wind turbine generators, presenting own experience means that it happened for real; "if we have an issue with one e-commerce order" [Ads 12, (12.5)] and "Expeditors is great at making that happen" [Ads 12, (12.6)] show that Gabriel gives a real example about an issue that The Kooples ever experienced and how Expeditors help them to overcome it, well, by delivering such examples that happened for real, those data can be classified as concrete example.

Deductive reasoning strategy is a strategy which comes with a general statement at the start then leads to specific conclusion in the end. Concerning the analysis findings, this strategy highly rare appeared. It appeared 3 times. It can be seen in advertisement 11 ( 3 data). The appearance of this strategy depicts that sometimes, freight forwarding advertisers present such unquestionable conclusion to influence audiences' mind either changing or reinforcing. For examples; "turns "customs" into an obstacle that most people just hope doesn't show up" [Ads $11,(11.3)]$ states a minor premise that most people think "customs" is an obstacle which obstruct their business so that they just hope it does not show up, "Customs is a tangle of taxes, fees, compliance, regulations, and local procedures" [Ads 11, (11.4)] states a major premise that "customs" is actually an important party in export-import processes which ensure that everything runs based on the existing regulations, "turn that Customs obstacle back into a well tuned part of your business and help you build a customs strategy that works" [Ads 11, (11.10)] shows a conclusion that "customs" is actually able to become a well tuned part of business.

Appropriate fear appeals strategy used to motivate audiences to change their behavior as the attempts to avoid those things which scared them. Concerning the analysis findings, this strategy is another highly rare applied. It is applied 3 times and can be found in advertisement 1 (3 data). The application of this strategy indicates that freight forwarding advertisers also use proper fear appeals to arouse their audiences' feeling and mind to change their behavior if they do not want to experience such terrible things during their shipping processes. For example; "long waiting time to receive your quotes" [Ads 1, (1.6)], "dealing with multiple quotations and unclear pricing" [Ads 1, (1.7)] and "not knowing where your shipment is" [Ads 1, (1.8)] depict some most worrying matters for customers when asking for quotations and shipping their cargoes; Kuenhe + Nagel presents those matters to arouse audiences' feeling of fear, so that they 


\section{International Journal of Linguistics and Discourse Analytics}

Vol.2, No.2, March 2021

P-ISSN 2721-8899 E-ISSN 2721-8880

have to choose the right partner in delivering their cargo if they do not want to experience such those terrible things.

Non-verbal behavior strategy is presented by modeling such emotion to audiences which the persuaders want their listeners to experience. In line with the findings, this strategy is also highly rare used. It is used 2 times and can be seen in advertisement 14 ( 2 data). The use of this strategy shows that the freight forwarding advertisers illustrate the emotions which they want their audiences to be felt through the gestures and facial expressions of the models to strengthen the persuasion in influencing audiences' mind. For example, "Welcome to a new world of local freshness" [Ads 14, (14.5)] points out where Nippon Express strengthen the statement with facial expressions of the models (a woman in Hong Kong, and a man in New York) where they look like a little bit shocked by the taste of the food when they eat it, they smile widely and nods their head to show their satisfaction for the taste.

Dynamism strategy is a strategy where the speakers are perceived as energetic and charismatic. Concerning the finding of the analysis, this strategy is extremely rare applied. It appeared once in advertisement 12 . The rare appearance of this strategy means that freight forwarding advertisers do not really regard the choice of charismatic and energetic person to be a speaker on the advertisement as important or effective, because freight forwarding is a business which deals with commodities. For example, "My name is Gabriel, I work for The Kooples and the Logistics Manager for North America" [Ads 12, (12.1)] indicates that Gabriel introduces himself as a North America logistics manager for The Kooples, as the logistics manager of French fashion brand, Gabriel of course perceived as charismatic, choosing him as the speaker is created to gain dynamism in advertisement.

Visual images to evoke emotion strategy is indicated by the use of pictures or images of emotion-arousing scenes to amplify the speech of the persuaders. In line with the finding, this strategy is also extremely rare applied in 18 freight forwarding advertisements. It is applied once and can be found in advertisement 11. The rare application of this strategy shows that freight forwarding advertisers do not really pay attention on the choice of emotion-arousing scenes pictures or images to amplify their speech; it is because freight forwarding advertisements are less dramatic and more realistic than any other advertisements. For example, "turn that Customs obstacle back into a well tuned part of your business and help you build a customs strategy that works" [Ads 11, (11.10)] shows where Expeditors illustrate using visual moving image along the narration, they illustrate it with three round images that symbolise customs broker, customs officer, and customer in sequence; and there is such green circular arrow which move around the side of customs officer's image, this green circular arrow means that those three parties can work together well.

There are two kinds of persuasive strategies which are not used in 18 freight forwarding advertisements above, they are use appropriate metaphor and simile and tap into shared myths. 
International Journal of Linguistics and Discourse Analytics

Vol.2, No.2, March 2021

P-ISSN 2721-8899 E-ISSN 2721-8880

Besides persuasive strategies, it also found that there are three ways of using persuasion applied in 18 freight forwarding advertisements which were uploaded on YouTube in 2019. They are the appeal to or creation of needs, social and prestige suggestion, and the use of emotionally loaded words and images.

Table 2. Ways of Using Persuasion

\begin{tabular}{|c|l|c|c|}
\hline \multirow{2}{*}{ No. } & \multicolumn{1}{|c|}{ Ways of Using Persuasion } & \multicolumn{2}{|c|}{ Data } \\
\cline { 2 - 4 } & \multicolumn{1}{|c|}{ Advertisement } & Frequency \\
\hline 1 & The Appeal to or Creation of Needs & $\begin{array}{c}1,2,3,4,6,7,8,9, \\
11,16,17,18\end{array}$ & 92 \\
\hline 2 & Social \& Prestige Suggestions & 12 & 12 \\
\hline 3 & The Use of Emotionally Loaded Words \& Images & $5,10,13,14,15$ & 29 \\
\hline
\end{tabular}

The ways how to use persuasion in the form of persuasion techniques also play essential roles in freight forwarding advertisements. The choice of persuasion techniques will affect the ability of persuasion in reaching the persuaders' goals.

The appeal to or creation of needs technique uses human's needs as the basic of persuasive statement. Concerning the findings, this way of using persuasion is the most frequently applied way of using persuasion. It is applied 92 times. It can be seen in 12 advertisements; they are advertisement 1, advertisement 2, advertisement 3, advertisement 4, advertisement 6, advertisement 7, advertisement 8, advertisement 9, advertisement 11, advertisement 16, advertisement 17, and advertisement 18 . The dominant application of this way of using persuasion depicts that this technique is highly regarded as effective in persuading people for freight forwarding field. The human's needs which used by freight forwarding advertisers in this technique are safety needs, esteem needs and cognitive needs. For examples; "faster, frequent and more reliable LCL service" and "confidence of delivering your cargo on time” [Ads 3] portray DHL's high dedication in serving their customers to meet people's safety and security needs by giving them a sense of freedom from fear; "an embedded sensor" and "centralized on a digital platform accessible 24/7 and analyzed in real time" [Ads 6] indicate Bolloré's high dedication to provide better facility to their customers and give people a sense of security.

The use of emotionally loaded words and images technique is applied by using buzzwords or some special words which can specify the products or some images with special character. In line with the findings, this way of using persuasion is moderately frequent applied. It appeared 29 times. It can be found in 5 advertisements; they are advertisement 5, advertisement 10 , advertisement 13 , advertisement 14 , and advertisement 15 . The appearance of 
International Journal of Linguistics and Discourse Analytics

Vol.2, No.2, March 2021

P-ISSN 2721-8899 E-ISSN 2721-8880

this technique means that freight forwarding advertisers, at some points, tend to present buzzwords and iconic words to assure and catch people's attention to arouse their curiosity about the company or the service that the company offers. For examples, "innovative multimodal solutions", "ecological footprint of freight trains" and "reduce $\mathrm{CO}_{2}$ by up to 80 percent" [Ads 10] depict that DB Schenker uses some buzzwords which become extremely popular in freight forwarding field lately; those are "innovative", "ecological footprint" and "reduce $\mathrm{CO}_{2}$ "; by presenting those buzzwords, people are more likely to pay close attention and curious about DB Schenker's innovation, those buzzwords indicate that this service is absolutely eco-friendly which nowadays become a point that highly demanded by society.

Social and prestige suggestion technique suggests people to buy a particular productgood or service - because many others do so (social suggestion) or some well-known person makes a recommendation (prestige suggestion). Referring to the analysis' finding, this technique is the most rarely used technique. It is used 12 times. It can be seen in advertisement 12 (all data). The rare use of this way of using persuasion shows that the freight forwarding advertisers have low tendency in persuading their audiences by using either social suggestion or recommendation from well-known people for commercial advertisements. For examples, " $\underline{M y}$ name is Gabriel, I work for The Kooples and the Logistics Manager for North America", "Expeditors has been great at reaching to our demands on a daily basis" and "it's a great customer experience" [Ads 12] portray some assertive statements by Gabriel which reassures people that Expeditors has a great capability in making their customer satisfied; this statement implicitly suggests people to choose Expeditors to become their partner by arousing more audiences' curiousity, attracting them to know more about Expeditors and making them eager to "taste" Expeditors services.

\section{Conclusion}

From the findings it can be concluded that the kinds of persuasive strategies occur in freight forwarding advertisements are competence, trustworthiness, dynamism, inductive reasoning, deductive reasoning, causal reasoning, credible evidence, new evidence, specific evidence, use evidence to tell a story, concrete examples, emotion-arousing words, nonverbal behaviour, visual images to evoke emotion, and appropriate fear appeals. The most frequently appeared persuasive strategy is causal reasoning; then followed with competence and trustworthiness.

The persuasions in freight forwarding advertisements are used through some ways called persuasion techniques. There are three ways of using persuasion in freight forwarding advertisements; they are the appeal to or creation of needs, social and prestige suggestion, and the use of emotionally loaded words and images. The persuasions in freight forwarding advertisements are mostly applied through the appeal to or creation of needs; the human's needs 


\section{International Journal of Linguistics and Discourse Analytics}

Vol.2, No.2, March 2021

P-ISSN 2721-8899 E-ISSN 2721-8880

which are applied in those persuasions are safety needs, esteem needs, and cognitive needs. 'Safety needs' is the belle of the ball in this case, because safety and security are fundamental matters in freight forwarding field. The more companies can influence their audiences mind that they guarantee high safety and security for their customers through their advertisements; the more people will be curious and interested in choosing those companies to be their partner.

Consider the tendencies of both dominant appearance of persuasive strategies and ways of using persuasion in freight forwarding advertisements, it shows that those persuasive strategies and persuasion techniques make freight forwarding advertisements become a realistic advertisement which mostly persuade their audiences through exposing company's excellences which can bring benefits to fulfill customers' needs during the processes of shipping goods. The choice of persuasive strategies and ways of using persuasion in freight forwarding advertisements are influenced by natural human instinct to fulfill their needs and also the target of audience segmentation

\section{References}

[1] Beebe, Steven A. \& Beebe, Susan J. (2015). Public Speaking: An Audience-Centered Approach (9th ed.). London: Pearson Education Limited.

[2] Brown, G. \& Yule, G. (1983). Discourse Analysis. Cambridge: Cambridge University Press.

[3] Fletcher, Winston. (2010). Advertising: A Very Short Introduction. USA: Oxford University Press.

[4] Jafari, Sepideh M. \& Mahadi, Tengku S.T. (2014). The Language of Advertisement and Its Features and Characteristics: Investigating the Issue from a Deeper View. International Journal of English Literature, 4(6), 9-14. Malaysia: TJPRC Ltd.

[5] Kinneavy, James L. (1971). A Theory of Discourse: The Aims of Discourse. New York: Prentice-Hall, Inc.

[6] Makosky, Vivian Parker. (1985). Identifying Major Techniques of Persuasion. Teaching of Psychology, 12(1), 42-43 
International Journal of Linguistics and Discourse Analytics

Vol.2, No.2, March 2021

P-ISSN 2721-8899 E-ISSN 2721-8880

\section{APPENDIX \\ 18 Freight Forwarding Advertisements (transcribed text)}

Advertisement 1: September 4, 2019 (https://www.youtube.com/watch?v=IHjS1uM_oeE)

"Kuehne + Nagel - eTrucknow: AI-enabled freight platform"

It may (1.1) take up to 24 hours until you hear from a vendor, once you receive the information you have to comb through the details, check for extra charges and then compare the quotes to find the best one.

Does this sound familiar to you? What if there is a better solution? What if (1.2) all you have to do is to provide your shipping details and receive the most competitive quotation instantly.

Are you ready to (1.3) make your life easier? Select the truck or let (1.4) eTrucknow recommend the most suitable truck for you. Simply click Book to confirm, and (1.5) get full visibility at every mile.

Say good bye to (1.6) long waiting times to receive your quotes. Say good bye to (1.7) dealing with multiple quotations and unclear pricing. Say good bye to (1.8) not knowing where your shipment is. And say hello to eTrucknow, (1.9) the only truck booking platform you will ever need. Get started today.

Advertisement 2: October 16, 2019 (https://www.youtube.com/watch?v=jtb7_5RDgAw)

"DHL Ocean Connect LCL - Global Network \& Expertise"

With DHL Ocean Connect LCL, (2.1) we operate the highest standards in the industry. We have a (2.2) truly global network offering a huge variety of pickup and delivery options, (2.3) meaning visibility, speed, and efficiency for you.

Our LCL services are provided by (2.4) our 4.000 trained ocean freight specialists, in (2.5) more than 330 locations offering more ocean loops and services than anyone else. (2.6) Each container is tracked and monitored from loading to arrival, (2.7) improving reliability and security.

Visit quote.mydhli.com or contact your local DHL Global Forwarding sales or customer service representatives.

Advertisement 3: October 16, 2019 (https://www.youtube.com/watch?v=5TV-ttkoLYk) "DHL Ocean Connect LCL - More Point Pairs"

With DHL Ocean Connect LCL, we offer (3.1) faster, frequent and more reliable LCL service, giving you the (3.2) confidence of delivering your cargo on time. We (3.3) have more direct services than any other freight forwarder. (3.4) With 45.000 point pairs to all major ports and inland points, which (3.5) cut transit times, avoid multiple 
International Journal of Linguistics and Discourse Analytics

Vol.2, No.2, March 2021

P-ISSN 2721-8899 E-ISSN 2721-8880

transhipment and double handling. (3.6) Cargoes handled and checked in our own approved warehouses, (3.7) reducing the risk of damage or miss routing.

Choose DHL Ocean Connect LCL, (3.8) it's fast, secure, and competitive. And you only ever pay for what you use.

Visit quote.mydhli.com or contact to local DHL Global Forwarding sales or costumer services representatives.

Advertisement 4: October 16, 2019 (https://www.youtube.com/watch?v=I5t5AHL3XkY)

"DHL Ocean Connect LCL - Dangerous Goods Handling"

With DHL Ocean Connect LCL, we can handle a wide range of products and commodities across our global warehousing network. Even cargo classified as dangerous goods, (4.1) our in-house dangerous cargoes experts (4.2) can process this cargo with the necessary care and (4.3) manage the needed documentations. (4.4) Ensuring it is segregated as needed before consolidation to (4.5) ensure compliances safety.

Visit quote.mydhli.com or contact to local DHL Global Forwarding sales or customer service representatives.

Advertisement 5: January 2, 2019 (https://www.youtube.com/watch?v=2g1NP1Jj9Jw)

"DSV - DSV Startup"

With (5.1) over 45.000 employees in 80 countries DSV is one of the largest transport and logistics companies in the world and one of the leaders in logistics innovation.

(5.2) DSV Startup, a unique venture helping start-ups grow. DSV (5.3) supports start-ups with professional consulting, including supply chain architecture design. We (5.4) ensure the success of start-ups and help them grow. DSV also (5.5) selects start-ups that are developing technological innovation to improve the supply chain.

DSV Start-Up, we're here to (5.6) make your start-up a success.

Advertisement 6: June 4, 2019 (https://www.youtube.com/watch?v=tGlJhlRFXkk)

"Bolloré Logistics Launches Real Time Monitoring"

When thinking about shipping goods overseas (6.1) some people imagine product

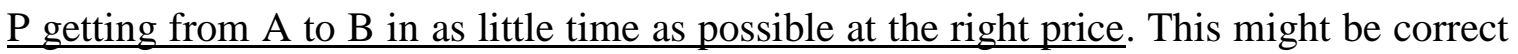
but it's not the full picture!

First, because (6.2) between A and B there are often different transport modes, many parties and complex journeys.

And (6.3) for shippers, product $\mathrm{P}$ is always specific, sensitive, critical, and they can't patiently wait and hope that it arrives safely at point B at time $\mathrm{T}$. 
International Journal of Linguistics and Discourse Analytics

Vol.2, No.2, March 2021

P-ISSN 2721-8899 E-ISSN 2721-8880

With real time monitoring, Bolloré Logistics invents an innovative service with end-to-end dynamic tracking of shipments and proactive management of alerts. Thanks to (6.4) an embedded sensor, all shipments data (localization, temperature, hygrometry, luminosity, impacts) are collected throughout the supply chain and (6.5) centralized on a digital platform accessible 24/7 and analyzed in real time!

(6.6) Real time monitoring is an integrated service for all transport modes. To (6.7) update every customer of any disruption (6.8) damages, threats, delay, and to prevent and correct deviations when the most sensitive goods travel throughout the world. Our customers can fully focus on what they value the most.

Advertisement 7: May 28, 2019 (https://www.youtube.com/watch?v=ucRKnAwPcco) “GEODIS - Enercon "La Désirade" Project by GEODIS France"

La Désirade project, (7.1) from Pointe-à-Pitre, Guadeloupe, to La Désirade, Guadeloupe. (7.2) 40 out-of-gauge components, including 8 E44 wind turbine generators from under-hook at origin. Offloading at the jobsite, experienced in-house experts, highly-tailored transportation, and (7.3) complex island access roads.

(7.4) Over $25^{\circ}$ slopes with (7.5) special equipment Ro-Ro barges. (7.6) Modular trailers, extendable trailers, with proven methodologies...

GEODIS, place of mind delivery.

GEODIS, (7.7) we logistic your growth.

Advertisement 8: May 28, 2019 (https://www.youtube.com/watch?v=Caz9o2NL1DY) "DB Schenker - DB Schenker connect 4 land"

An effective new way to ship your pallets using the biggest land transport network in Europe. Click, ship, done!

Click, from door to door. (8.1) Simply select all the details of your origin and destination. (8.2) Thousands of destinations on a single platform! (8.3) Specify your cargo and select the package type of your choice! (8.4) Perfect for individual items! (8.5) Adjust your shipment details, find your preferred shipping option, $(8.5)$ select the product that perfectly fits your needs! (8.6) Choose the price/lead-time combination that suits you best.

(8.7) Make shipping something you do effortlessly! Click. Ship. Done!

Advertisement 9: June 5, 2019 (https://www.youtube.com/watch?v=bJQKeHc9FE4) "DB Schenker - DB Schenker connect 4 air"

Click. Ship. Done! And effective new way to quote, book, track. 
International Journal of Linguistics and Discourse Analytics

Vol.2, No.2, March 2021

P-ISSN 2721-8899 E-ISSN 2721-8880

Quote. To airport or to door. The global network in your hands! (9.1) Simply select all the details of your origin and destination. (9.2) Get instant quotes and manage your shipment online. (9.3) Get in touch if you need support with your booking request. (9.4) Define your shipment with just a few clicks. Get instant quotes and various options.

Book. All details will be completed automatically.

(9.5) Track. connect.dbschenker.com

(9.6) Operational excellence combined with digital ease of use.

Click. Ship. Done! DB Schenker connect 4 air.

Advertisement 10: May 28, 2019 (https:/www.youtube.com/watch?v=Z9FlguK4Fe8) "DB Schenker - Multimodal and Dedicated Solutions"

(10.1) Every logistics expert knows that there is no such thing as a one-size-fitsall mode of transportation. That's why DB Schenker combines the specific advantages of each mode by designing (10.2) innovative multimodal solutions dedicated for our customers. We serve clients with a broad range of multimodal customer solutions - (10.3) from conventional rail to intermodal, from standard loads to special transports, from heavy goods to high value, from north to south and east to west, from seaport to railport, from semi-trailer to roll-trailer.

DB Schenker Multimodal Solutions (10.4) combines the specific advantages of each transport mode and hence combines the outstanding (10.5) ecological footprint of freight trains with the flexibility of trucks.

DB Schenker Multimodal Solutions can (10.6) reduce $\mathrm{CO}_{2}$ by up to 80 percent compared to conventional transport by road. Our expertise is (10.7) customizing the optimal door-to-door solutions by combining rail, road and short sea.

Advertisement 11: July 18, 2019 (https://www.youtube.com/watch?v=5acPZLmObR8)

"Expeditors - What is your customs strategy?"

You've probably heard "It's stuck in customs" before.

(11.1) Missing shipment... "It's stuck in customs".

(11.2) It didn't get there on time... "It's stuck in customs".

This impression (11.3) turns "customs" into an obstacle that most people just hope doesn't show up. But that's not really the case, and 'hope' is not a strategy. However, (11.4) Customs is a tangle of taxes, fees, compliance, regulations, and local procedures. Our strategy is simple, (11.5) customs brokerage is a knowledge based service. (11.6) The more knowledgeable we are, and the better we are at leveraging that knowledge, the better we can serve our customers. 
International Journal of Linguistics and Discourse Analytics

Vol.2, No.2, March 2021

P-ISSN 2721-8899 E-ISSN 2721-8880

Because (11.7) our people are local, they have local brokerage experience and expertise. With a birds eye view of your organization and the ever shifting trade landscape we can give insights and help you build strategies. (11.8) Strategies that streamline your process, accelerating your supply chain and driving out cost.

We are (11.9) a compliance first company who make our customers goals our own. We can (11.10) turn that Customs obstacle back into a well tuned part of your business and help you build a customs strategy that works.

Advertisement 12: April 11, 2019 (https://www.youtube.com/watch?v=f9RnLqNYQBg) "Expeditors - Expeditors Customer Testimonial: The Kooples"

(12.1) My name is Gabriel, I work for The Kooples and the Logistics Manager for North America. We are a (12.2) French fashion brand, headquartered in Paris, with (12.3) North American operations headquartered here, in New York.

(12.4) Expeditors has been great at reaching to our demands on a daily basis. For example, (12.5) if we have an issue with one e-commerce order, maybe it was received late or it's a priority order for us, we want to be able to ship that out as soon as possible. (12.6) Expeditors is great at making that happen. (12.7) One of our biggest pain points is storage space. So it's important for (12.8) Expeditors to be able to work with us to create more space as needed.

(12.9) We need the specific packing list, specific carton labels, specific packaging for all these orders, and so we're able to work with Expeditors hand in hand so that (12.10) they can meet all those requirements before we start shipping. (12.11) They are reactive to our demands and able to work with us on specific problems that might not pertain to other clients. So, overall (12.12) it's a great customer experience.

Advertisement 13: March 22, 2019 (https://www.youtube.com/watch?v=xeNP-O_YII) "Nippon Express Pharmaceutical Products Logistics"

We find the way. Nippon Express.

Pharmaceutical products, (13.1) transporting them requires absolute quality control. For Nippon Express, having such (13.2) time critical merchandise is part of our proven logistics services. Because (13.3) quality control is of the utmost importance. (13.4) Our transportation and storage networks help move pharmaceutical products around the globe. (13.5) Worldwide delivery above and beyond. Nippon Express Global Logistics.

Advertisement 14: March 22, 2019 (https://www.youtube.com/watch?v=R4P_uIN_K0w) "Nippon Express - Nippon Express Food Logistics" 
International Journal of Linguistics and Discourse Analytics

Vol.2, No.2, March 2021

P-ISSN 2721-8899 E-ISSN 2721-8880

We find the way. Nippon Express.

Dam never even likes sushi before, oh now his passion is (14.1) Aji from Amakusa. What changes Dam? Nittsu Food Logistics, (14.2) our new technology (14.3) keeps that just caught freshness and our global network (14.4) delivers the subtle taste of Japanese delicacies around the world.

(14.5) Welcome to a new world of local freshness. Nippon Express Global Logistics.

Advertisement 15: July 4, 2019 (https://www.youtube.com/watch?v=-Q_2g9aFsX0)

"Nippon Express - We Find the Way"

We find the way, Nippon Express.

(15.1) No matter what the obstacle or where in the world we face it, (15.2) Nippon Express is not daunted. (15.3) We focus only on overcoming the challenge. (15.4) Searching until we find the single best way to do what needs to be done.

(15.5) Welcome to the future of logistics. (15.6) We find the way, Nippon Express.

Advertisement 16: Dec 12, 2019 (https://www.youtube.com/watch?v=1WGGCyURVQ4)

"Yusen - Yusen Logistics Supply Chain"

We know (16.1) you can't always predict the future. (16.2) Unexpected circumstances create sudden demand. That's why, you need a team of (16.3) dedicated supply chain experts with global insight into your industry.

Using our (16.4) industry-leading IT system helping you to (16.5) analyze, predict, control and optimize every aspect of your supply chain. So you can focus on what's most important to you. We seamlessly (16.6) integrate our services with your business to (16.7) keep you on top of your operation anytime, anywhere.

Connected Supply Chain Solutions. Yusen Logistics, (16.8) insight into action.

Advertisement 17: June 12, 2019 (https://www.youtube.com/watch?v=ckAcPHXuMyQ)

"Yusen - Yusen Logistics Automotive"

We know (17.1) every vehicle is unique and the manufacturing process is complicated. That's why, you need a team that understands your supply chain, always looking for improvements, by (17.2) using Kaizen best practices. To secure your production line and quality standards and on time delivery, you're looking for a strategic partner that works with you to (17.3) deliver air, ocean freight and land transportation; warehousing and distribution services; and supply chain solutions - globally. 


\section{International Journal of Linguistics and Discourse Analytics}

Vol.2, No.2, March 2021

P-ISSN 2721-8899 E-ISSN 2721-8880

Services that can all be (17.4) managed through our dedicated automotive control tower, (17.5) to provide visibility, consolidation, and optimization. For us, (17.6) it's about more than moving your goods, it's about getting every detail right and providing support when you need it. Our global network (17.7) with over 570 locations, transports vehicles and parts all over the world, to keep your business moving anytime, anywhere.

(17.8) Your trusted partner in automotive logistics, Yusen Logistics. Insight into action.

Advertisement 18: August 6, 2019 (https://www.youtube.com/watch?v=Ta0ZYP1dBLk) "Yusen - Yusen Logistics Healthcare"

(18.1) We know that service and quality are important to you ensuring that it is delivered time and time again. You're looking for a strategic partner that works with you to (18.2) deliver air and ocean freight forwarding; warehousing and distribution services; and supply chain solutions - globally.

Services that can all be (18.3) managed through our dedicated healthcare control tower, to (18.4) provide visibility, consolidation, and optimization. For us, (18.5) it's about more than delivering a product, it's about getting every detail right. (18.6) With 24 hour traceability, worldwide GDP and quality standards, real time global visibility, and temperature control across all modes. It's about providing a valuable service that's tailored to you, a service where quality is at the forefront (18.7) with Kaizen best practices at its heart. (18.8) Our key values keep our customers at the centre of everything we do; connected, committed, creative. And keep us delivering on our brand promise to create better connections.

(18.9) Healthcare logistics designed by us, specifically for you. Yusen Logistics, insight into action. 